\title{
A Survey of E-Learning Implementation Best Practices in Jordanian Government Universities
}

\author{
doi:10.3991/ijac.v4i2.1627 \\ Haroon Altarawneh \\ Arab International University (AIU), Syria
}

\begin{abstract}
The facility to connect people and information around the world, the Internet is before now having a major impact on the traditional education. Currently, students can easily access the online course materials anytime anywhere. Internet also amplifies the complication of the course materials development. As the learning idea is taken by a student in the e-learning environment, traditional teacher determined learning model is no longer appropriate. As a result, student-centered course materials which are prepared based on individual student's learning expectation, styles, interests and individual academic background become critical.
\end{abstract}

The quick growth of Internet technologies and web based environments, e-learning has become a major trend in the education area. Most of the e-learning contents are still developed in same traditional educational ways; Jordanian government Universities followed a different ways in implementing e-learning systems. The objective of this research is to understand the extent of E-learning implementation practices currently in use. To achieve this objective, a survey of E-learning implementation practice in Jordanian universities was conducted. A detailed description of the survey procedures is provided in this paper.

The units of analysis for the survey were Jordanian government universities undertaking E-learning systems implementations. The target population included all Jordanian government universities which implement E-learning systems by second party as well as in-house e-learning system development. The results showed that there is a weakness in applying E-learning implementation practices in Jordanian government universities. The results of the study lead to important recommendations to improve E-learning implementation practice in Jordanian government universities in Jordan like that the development teams should be multidisciplinary and universities should pay attention to the quality management and standards. The results also compared to some case studies from European countries. The analysis also showed that there are significant differences in the levels of adoption of E-learning implementations practices between European universities and Jordanian government universities.

Index Terms-E-learning system, best practices, Jordan Universities.

\section{INTRODUCTION:}

Higher education in Jordan began with the second half of the twentieth century, namely the sixties, when numerous Teachers' Colleges were established throughout the country. Their establishment provided the necessary teaching manpower needed to meet the high demand on school education characterizing that era.
At present, there are ten public and thirteen private universities in Jordan. The Bachelor's degree is offered at both types, while Master's and Doctorate degrees are confined to public universities.

In recent years, pressures have emerged from policy makers and other stakeholders to embed e-learning technologies in mainstream higher education. The interest in implementing e-learning in higher education systems throughout the world has been influenced by a number of pressures and drivers. According to Hammond [1] higher education institutions exist within political, cultural and social contexts which shape policy and practice. Within this context the main drivers are national policies and priorities with regard to economic and social development, beliefs and expectations of the role of education in terms of supporting those priorities, and developments in educational technologies which have the potential to enable the system to achieve these objectives. These three drivers are interdependent, and influence the adoption of learning technologies in the institutions through the role of funding and support agencies [1]. According to this model, the pressures on institutions to adopt e-learning are substantial, however, the ability to do so can be constrained by numerous barriers, not least the availability of funding.

E-learning is defined as a network or online learning that takes place in a formal context and uses a range of multimedia technologies [2]. It is essentially a learning system that is supported by electronic hardware and software either online (synchronous) or offline (asynchronous). The learning is carried out either individually or on a small or large group basis and can be used as a hybrid to the face-to-face format, or exclusively in open and distance learning (ODL). As such, e-learning is not confined to the boundaries of the online format but also includes the offline format using any form of electronic media to facilitate the teaching and learning processes.

E-learning is becoming increasingly prominent in tertiary education, with universities increasing provision and more students signing up. But is it actually changing the way universities teach and students learn, or is it simply a case of students typing up their essays on computers and professors sending them course reading lists or work assignments by e-mail.

In educational institutions (e.g., high schools, universities, etc.) and in work life, the question of how to utilize modern information and communication technologies for learning purposes is important. E-learning in its broadest sense refers to any learning that is electronically enabled. In a slightly narrower sense, it is learning that is enabled by the application of digital technologies [3].

Implementing an e-learning initiative can be very rewarding and equally tricky if you've never launched one 
before. There are myriad decisions to be made and important considerations to be built into the implementation action plan. The greatest determinant of success can be summed up in two words: Be prepared.

As defined by the American Society for Training and Development (ASTD), e-learning "covers a wide set of applications and processes, such as Web-based learning, computer-based learning, virtual classrooms, and digital collaborations". In the context of this study e-learning is defined as Internet based learning that is focused on the delivery of content (text, audio, video, animation, simulation) in a training format. Each stage of the e-learning process requires thoughtful analysis and investigation of how to use the Internet's potential in concert with instructional design principles and issues important to various dimensions of the e-learning environment. Therefore, institutions and individuals venturing into e-learning initiatives should explore the requirements necessary to create a successful e-learning experience. This is exactly the area where this study can be a helpful too [4].

\section{SURVEY METHODOLOGY}

The units of analysis for the survey were Jordanian government universities undertaking e-learning system. The target population included all Jordanian government universities which implement E-learning systems by second party as well as in-house e-learning system development.

Prior to the data collection, the survey instrument was pre-tested to enable clarification of constructs; to provide the means of operationalising selected constructs; and because pre-tests can be useful in qualitatively establishing the reliability, construct validity, and content validity of measure. In order to locate and correct weaknesses in the questionnaire, the questionnaire was pre-tested using face-to-face interviews with 20 random respondents. The selection of interviewees for these pre-tests was designed to obtain maximum feedback from respondents in various roles.

Prior to the pre-test, the following checklist was used to review the questionnaire instrument:

- Will the words be uniformly understood?

- Do the questions contain abbreviations or unconventional phrases?

- Are the questions too vague?

- Is the question too precise, biased or objectionable?

- Is it a double-barrel question?
- Does it have a double negative?

- Are the answer choices mutually exclusive?

- Has too much knowledge been assumed?

- Is the question technically accurate?

- Are the questions too cryptic?

During the pre-test, the respondents completed the questionnaire in the presence of the researcher, and identified any difficulties with interpretation of words or questions. As well as testing the reliability and construct validity, the pre-tests served as 'dry runs' for the final administration of the instrument.

The feedback was not adequate. So, some parts of the questionnaire were translated into Arabic Language (the mother tongue of respondents), and the pre-test was carried a second time.

The sample used consisted of ten university in Jordan. Universities were eligible for inclusion in the survey when they have had implemented e-learning systems during the last two years. The first section collects information on the respondent's background. This includes current position, past experience. The second section, entitled e-learning system implementation best practices, concentrates on the adoption of e-learning system implementation best practices by the respondent's university. These include organizational issues, standards and procedures, e-learning metrics, control of the development process, and tools and technology. The third section is interviews with faculty staff, project mangers, and developers. The objectives of the interviews were to recognize the reasons, problems and obstacles of the implementation process in selected universities.

\section{THE StATISTICAL ANALYSIS:}

During the survey, we found inconsistency between universities with respect to the titles being given to elearning implementers. However, we found a number of similarities in the tasks implementers from different universities were responsible for during the life-cycle of an elearning system project.

\section{A. Respondents' Background:}

This section contains seven dimensions. Figure (1) shows the distribution of respondents by current position. The majority of the respondents were students and faculties' staff. The second highest ratio is Technical members $(22 \%)$. project or team leaders constituted $17 \%$, and mangers were $10 \%$.

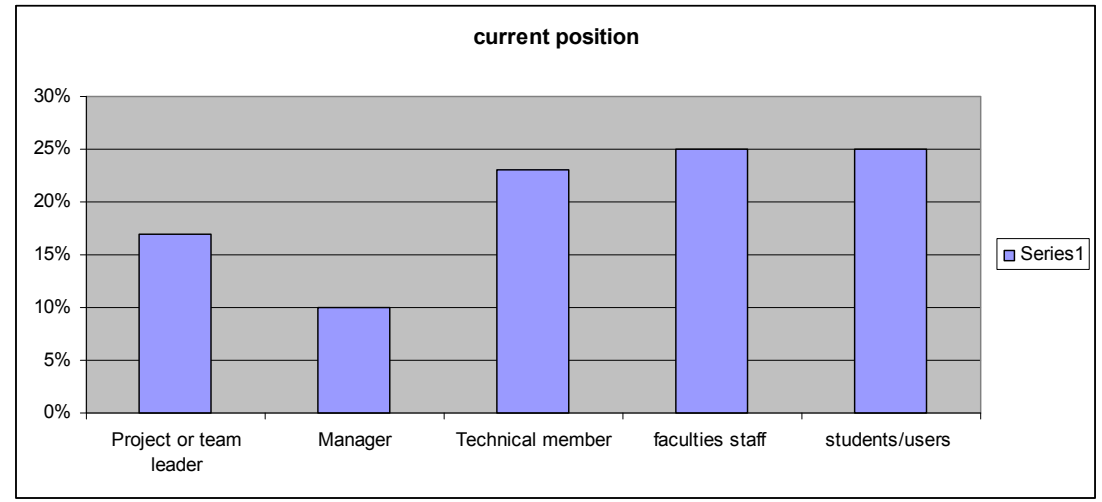

Figure 1. Current Position 
With regard to the current work activities (see Figure $2)$; the highest ratio was for system requirement (38\%). System content management got (16\%). System Design was $(15 \%)$. system test and integration was $(12 \%)$. System Code and unit test was $(10 \%)$. Software quality assurance got $(5 \%)$, and lastly others $4 \%$.

With regard to the years of experience in present organization (Figure 3), the group of 5 years and less got the highest ratio $(65 \%)$. The second group was the (6-10) years with $20 \%$, and the 11 years and above got $15 \%$.

Concerning the level of experience with e-learning development (see Figure 4), little knowledge of e-learning system development obtained $63 \%$, basic knowledge of e-learning system development 20\%. Advanced knowledge of e-learning system development $10 \%$, and lastly no knowledge of e-learning development $7 \%$.

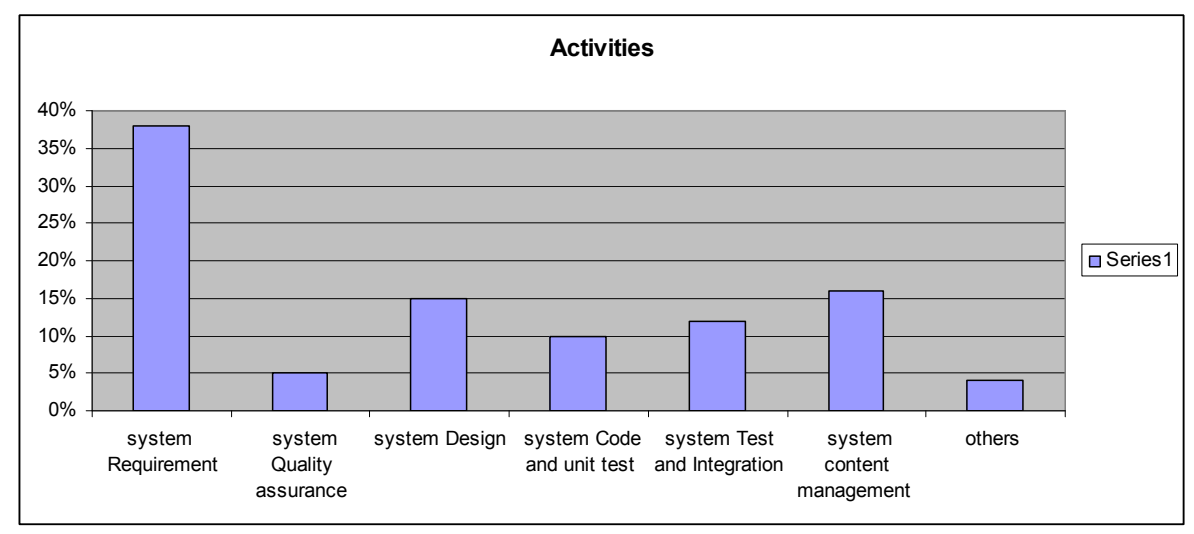

Figure 2. Activities



Figure 3. Experience in present university

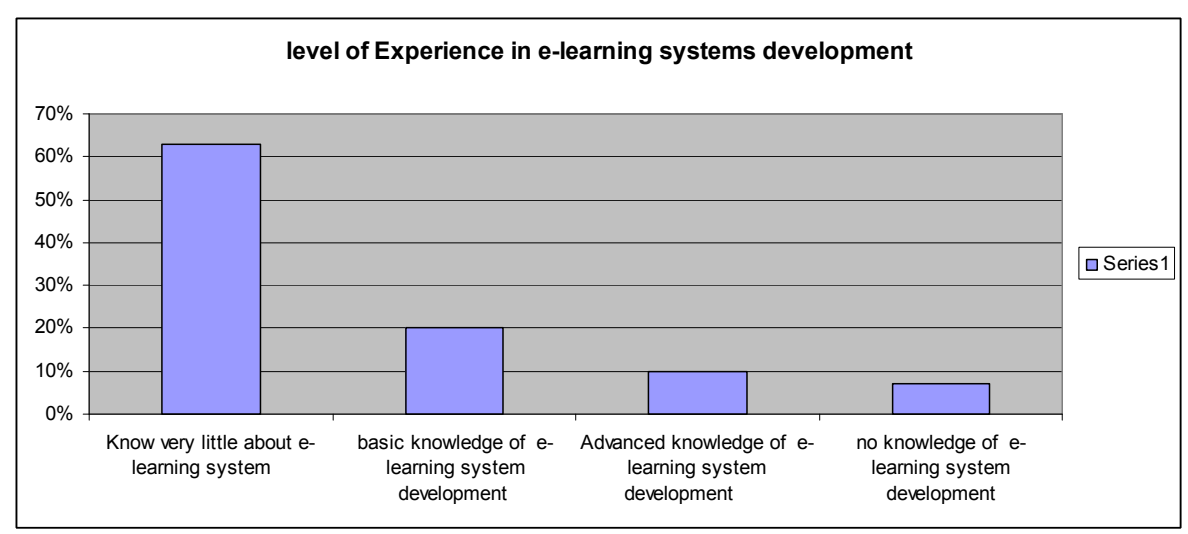

Figure 4. Level of Experience with E-learning system development 
PAPER

\section{A SuRVEy of E-LEARning IMPLEMENTATION BEST PRACTICES IN JORDANIAN GOVERNMENT UniVERSITIES}

Regarding the problems facing e-learning implementation(see Figure 5), Technical (the technology problem) got the highest ratio (80\%), Administrative (organizational) got (70\%), Cultural problems got (60\%), Didactic/ pedagogical got $(40 \%)$, and lastly Legislative $(30 \%)$.

Figure (6) shows the technical problems, where insufficient computer labs got the highest ratio $(70 \%)$, the second highest ratio was the Non-proficient equipments $(55 \%)$, insufficient Band width got (40\%), Hardware- software incompatibility got (30\%), and lastly Internet Inaccessibility $(20 \%)$

Concerning the administrative problems see figure (7), Insufficient funds to develop an e-learning system got the highest ratio (83\%), The lack of e-learning strategies and politics $(67 \%)$, The lack of clear, accessible communication channels $(51 \%)$, The lack of interest regarding e-learning education $(49 \%)$, and lastly The human resources strategy $(43 \%)$.

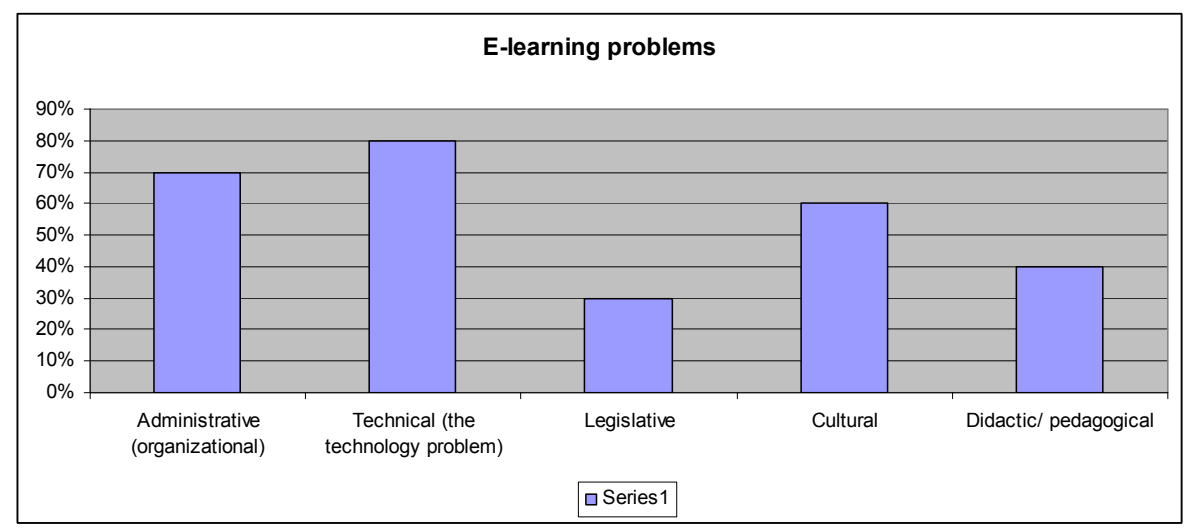

Figure 5. E-learning Problems

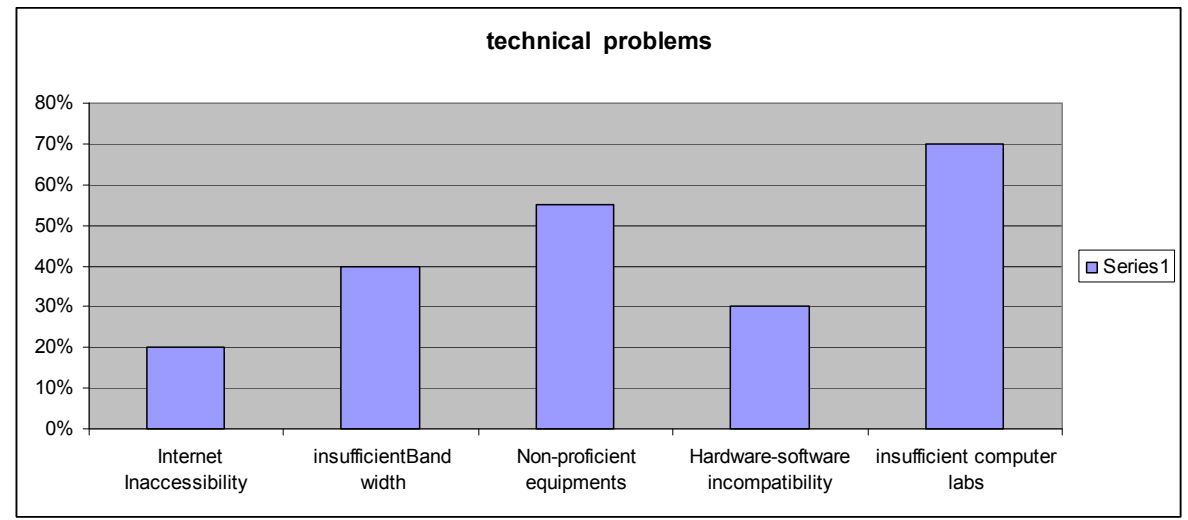

Figure 6. technical Problems

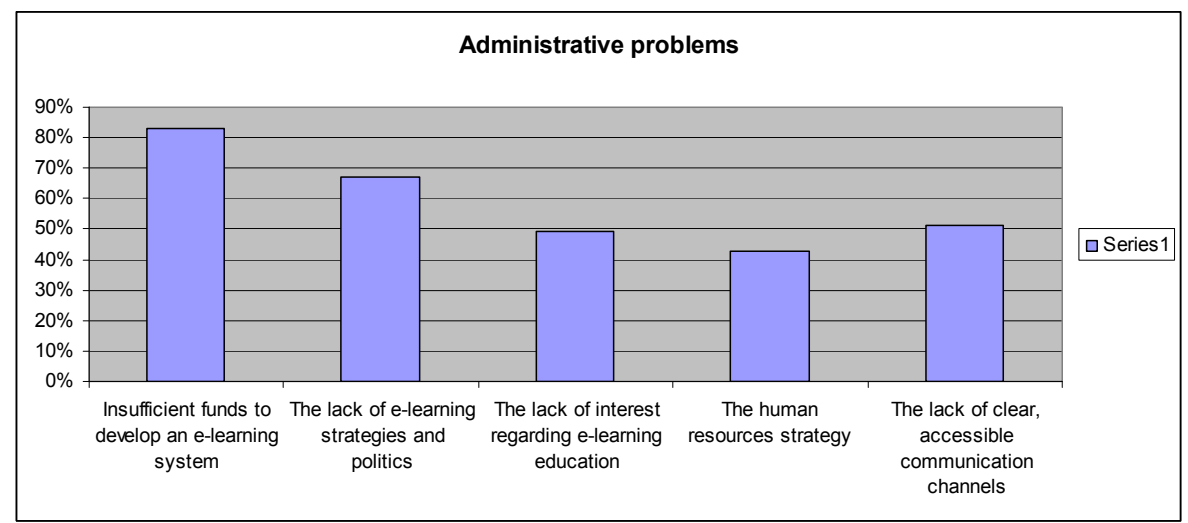

Figure 7. Administrative Problems 
PAPER

A SURVEY OF E-LEARNING IMPLEMENTATION BEST PRACTICES IN JORDANIAN GOVERNMENT UnIVERSITIES

\section{B. Organizational Issues:}

This section contains eight questions. Figure (8) shows that most of the respondents have answered 'No' to most of the questions. The questions with the highest 'No' percentages were as follows:

(4) Is a change control function established for each elearning system project? The ratio of those who answered 'No' was $69 \%$.

(5) Is there a required training program for all newlyappointed e-learning system managers which are designed to familiarize them with in-house e-learning project management procedures? The ratio of those who answered 'No' was $67 \%$.

(1) Does each e-learning system have a nominated project manager? The ratio of those who answered 'No' was $65 \%$.

(3) Does e-learning system Quality Assurance (eLQA) function exist within an independent reporting line from elearning system project management? Its ratio was 55\%.

Finally, (8) Where other non-web resources are critical to the success of the project, is there a procedure for ensuring their availability according to plan? Its ratio was $37 \%$.

\section{Standards and Procedures:}

This section contains twelve questions. Figure (9) shows that most of the respondents have answered 'No' to most of the questions. The questions with the highest 'No' percentages were as follows:

(10) Are there procedures to ensure that the functionality, strengths, and weaknesses of the "system" which the e-learning system is replacing are formally reviewed? Its ratio was $70 \%$.

(12) Is independent testing conducted by users (or appropriate representatives) under the guidance of e-learning Quality Assurance before any system or enhancement goes live? Its ratio was $65 \%$.

(1) Do management formally assess the benefits, viability, and risk of each e-learning project prior to making contractual (or internal) commitments? Its ratio was 55\%.

Finally, (4) for each project, are independent audits (such as inspections or walkthroughs) conducted for each major stage in the e-learning development process? Its ratio was $37 \%$.

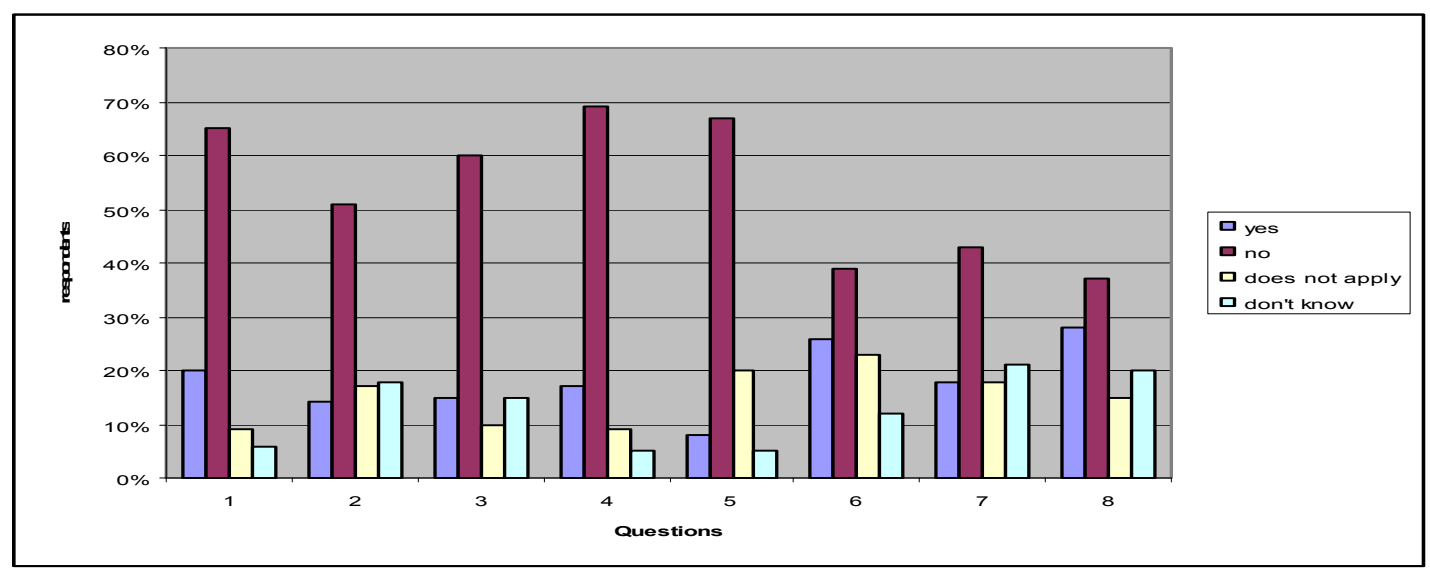

Figure 8. Organizational Issues

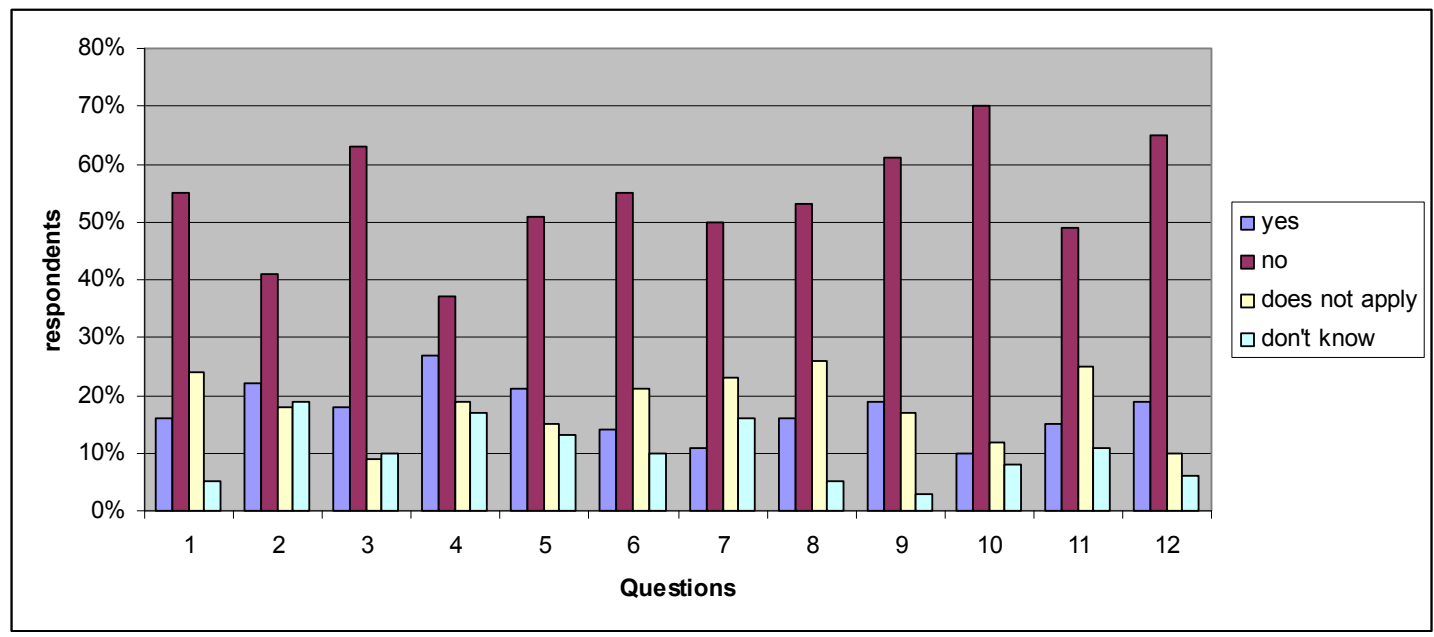

Figure 9. Standards and Procedures 
PAPER

A SURVEY OF E-LEARNING IMPLEMENTATION BEST PRACTICES IN JORDANIAN GOVERNMENT UnIVERSITIES

\section{E-learning Metrics:}

This section contains eight questions. Figure (10) explicates that most of respondents have answered the questions with don't know. The questions with the highest 'Don't know' percentages were as follows:

(3) Are statistics on the sources of errors in e-learning code gathered and analyzed for their cause, detection and avoidance measures? Its ratio was $68 \%$.

(7) Are post-implementation software problem reports logged and their resolution effectively tracked and analyzed? Its ratio was $60 \%$.

(5) Is "earned value" project tracking used throughout the e-learning development process (actual versus planned deliverables analyses, designed, unit tested, system tested, acceptance tested over time) to monitor project progress? Its ratio was $58 \%$.

Finally, (2) Are records of e-learning application size maintained for each e-learning application configuration item, over time, and fed-back into the estimating process? Its ratio was $50 \%$.

\section{E. Control of the Development Process:}

This section contains six questions. Figure (11) explicates that most of respondents have answered the questions with "No". The questions with the highest 'NO' percentages were as follows: (6) Do procedures exist to ensure that every required function is tested/verified? Its ratio was $71 \%$. (1) Are estimates, schedules and subsequent changes produced only by the project managers who directly control the project resources and are fully aware of their abilities and availabilities? Its ratio was $63 \%$. (3) Is there a procedure for controlling changes to the elearning system requirements, designs and accompanying documentation? Its ratio was $56 \%$. Finally, (5) is there a mechanism for assuring that regression testing (i.e. the forced re-run of all previous tests prior to any new tests) is routinely performed during and after initial implementation? Its ratio was $15 \%$.

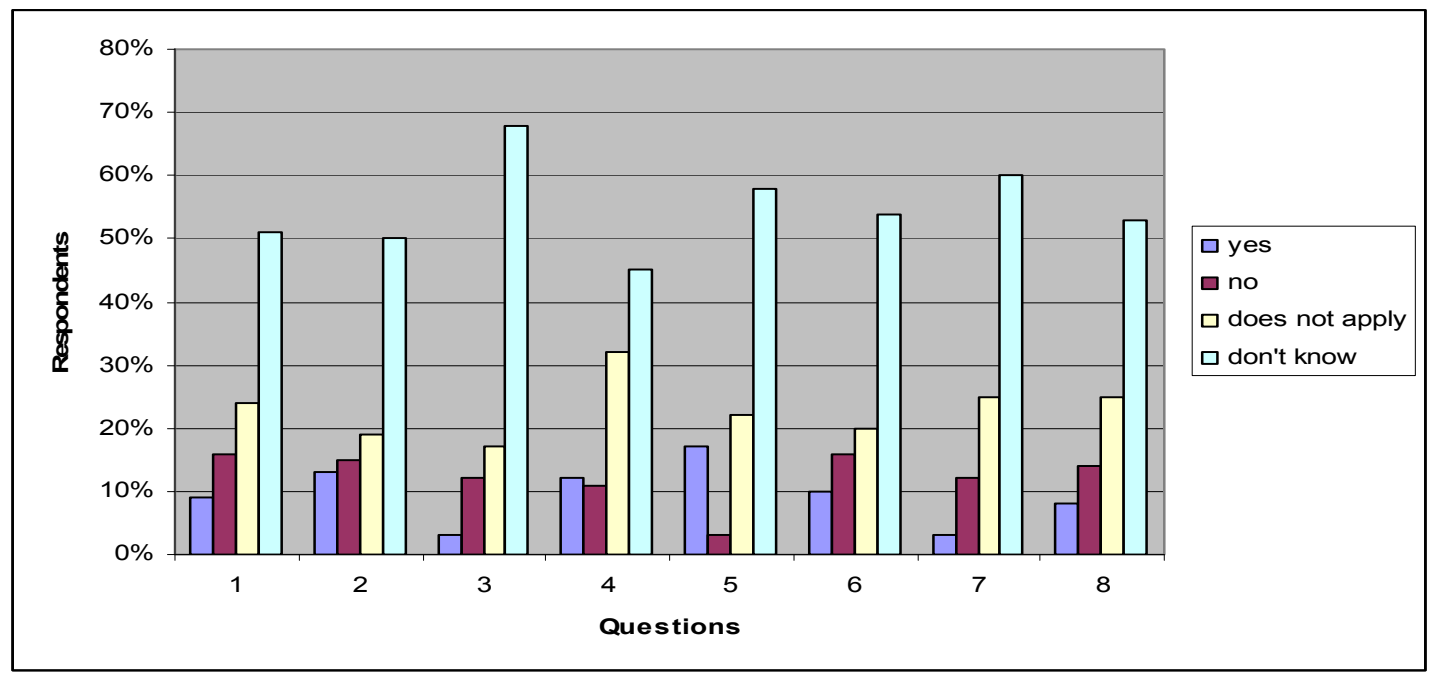

Figure 10. E-learning Metrics



Figure 11. Control of the Development Process 


\section{F. Tools and Technology:}

This section contains seven questions. Figure (12) explicates that most of respondents have answered the questions with 'Yes'. The questions with the highest 'Yes' percentages were as follows:

(5) Are prototyping methods used in ensuring the requirements elements of the e-learning system? Its ratio was $79 \%$.

(1) Are software tools used to assist in forward and/or backward tracing of e-learning system requirements to elearning designs through to code? Its ratio was $74 \%$.

(2) Are design notations used in e-learning design? Its ratio was $55 \%$.

(3) Are automated testing tools used (for example for capturing and replaying tests, or for ensuring logic paths coverage)? Its ratio was $43 \%$.

(6) Is a data dictionary available for controlling and storing details of all data files and their fields? Its ratio was $40 \%$.

(4) Are software tools used for tracking and reporting the status of the e-learning system? Its ratio was 30\%.

Finally, (7) Are software tools used for e-learning project planning, estimating, scheduling, and critical path analysis? Its ratio was $28 \%$.

\section{G. Interviews:}

We investigated the problems associated with cost and effort estimation, the success rate of e-learning systems development, implementation and the reasons for project failure, by asking every interviewee the following questions:

1. How often do your E-learning system projects run over time?

2. What are the reasons for projects running over time?

3. How often do your E-learning system projects run over budget?

4. What are the reasons for E-learning system projects running over budget?

5. How many E-learning system projects proposed result in a delivered system?
6. What are the prime reasons for projects not resulting in a delivered E-learning system?

7. Do you have a well-defined and documented development process for building E-learning system projects?

8. What mechanisms do you employ to measure the success of a project?

9. At what stage in the development process do you employ these mechanisms?

10. What software tools do you use when developing a E-learning system project, what tasks do you use them for, and at what stage in the development are they used?

11. What is the average length of an E-learning system project, from inception to first delivered working system?

The survey was conducted in a qualitative manner using an in-depth one-to-one interview technique. All the answers were recorded on paper by the interviewer conducting the survey. The formal answers given to questions 1 and 3 did not correspond with the informal discussions held with mangers of projects in this survey. We concluded that we were often being given political answers to questions 1 and 3. In our opinion one of the prime reasons for going over budget on a software or E-learning system project is due to a failure to deliver on time.

Answers to questions 1 and 3 must be treated with some scepticism, we often felt that we were getting the university's politically approved answers to these questions. Questions 2 and 4 showed a lot of consistency in the interviewee's answers. All the interviewees mentioned one of the reasons for E-learning system projects running over time to be because of poor communication between themselves and their clients, late project changes by their clients, or poor understanding of the process of building an E-learning system on the behalf of the client. In our opinion these answers clearly indicate a problem with the requirements and analysis phases of most e-learning process.

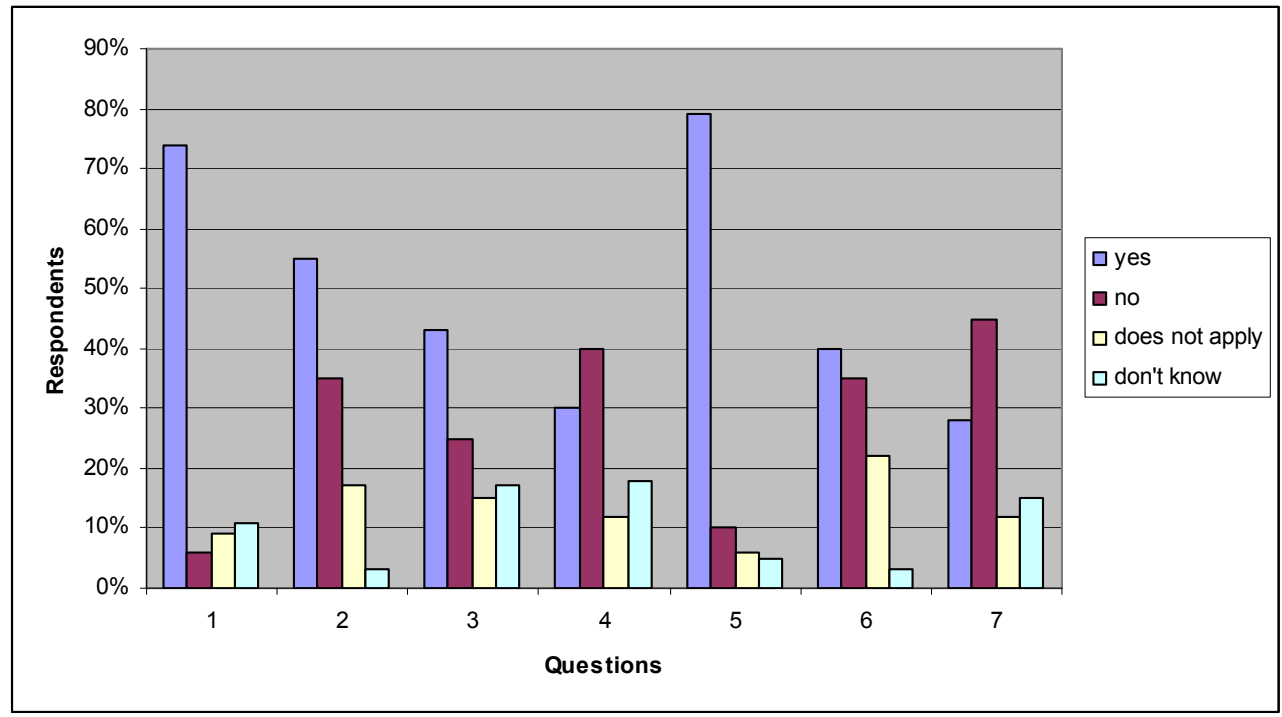

Figure 12. Tools and Technology 
Other reasons given for projects not delivering on time include poor project management, poor project effort estimation techniques, and inadequate testing procedures. The primary reason given for projects running over budget was also down to problems with the requirements phase of the E-learning system process. Other reasons given for projects running over budget include lack of resources, poor delivery of data/content, poor management, lack of professionalism and unforeseen costs.

Question 5 suffered similar problems to questions 1 and 3 previously. The answers varied in order to draw any valid conclusions. However like questions 2 and 4, question 6 was very illuminating, with five interviewees claiming lack of budget, eight interviewees claiming problems with analysis and requirements phases in their E-learning system processes seven interviewees claiming project management problems as a reason for project failure. The answers to question 6 further strengthen our claim that Elearning system processes being used in industry need to focus more on project management, analysis and requirements phases if they are going to increase the rate of successful projects.

For question 7 five of the twenty interviewees claimed to have a development process in place for building Elearning system. The others answers were using a development method that had been created in house.

When asked to describe the process of building an Elearning system all the interviewee's processes started with the development of a project Scoping document, which covered the requirements and design phases of an Elearning system project. The Scoping document was one of only two deliverables that were created in the vast majority of E-learning system processes used by the universities in this survey. The E-learning system being the second deliverable. For question 8 and 9 eight of the interviewees considered a project to be successful primarily if the client was happy with the deliverable, ten interviewees mentioned achieving budget and time estimates as a mechanism for measuring a project's success. Only tow interviewees mentioned passing a Testing phase as a mechanism for measuring project success and not one interviewee mentioned involving end users as a mechanism for validating the success of a project. All the interviewees measured success at the end of a project's lifecycle, or after the project had ended. There were no mechanisms in place to properly validate the project deliverables during development.

Question 10 was designed to highlight any tools that were being used consistently throughout the industry at specific stages in the development process or for specific E-learning system tasks. Unfortunately the question did not work very well with a number of the interviewees, who were unsure of my descriptions of the identified stages. However the answers showed some consistency among different universities in terms of the tools used e.g. Photoshop was the most popular raster image manipulation tool and Outlook Express was the most popular email client across all major operating system platforms. And all universities depend on tools in most cases of E-learning system. For question 11, the average development lifecycle time for the development of E-learning system is 6 months. Most E-learning system projects have a life cycle of 3 to 12 months.

\section{RESULTS}

The statistical analysis shows that e-learning metrics got the lowest ratio; which implies that the majority of respondents are not familiar with this practice. Tools and technology got the highest ratio; which implies that this practice is the most applied practice in these universities, and this reflects the widespread use of these tools in the development process worldwide. Organizational issues, standards and procedures and control of the development process got similar ratios. But, for the organizational issues, and standards and procedures, the majority of respondents answered with "No". This implies that the majority of respondents are not familiar with these two practices. For the control of development process practice the majority of respondents answered with "no". This implies that the respondents are not familiar with this practice, but they don't apply it, and this leads one to say that the implementation process models used by these universities are ad hoc.

The previous results show that there is a weakness in the application of e-learning system best practices in Jordanian universities, especially in organizational issues, standards and procedures, e-learning metrics, and the control of the development process. Universities show a high adoption ratio for using web tools and technology in the development and implementation process of e-learning systems.

The respondents provided a wide variety of information about their e-learning implementation practices, and it is difficult to draw overarching generalizations based on the evidence provided. Nevertheless, three main conclusions can be drawn:

1. there is a wide variety of different e-learning practices in Jordanian universities.

2. e-learning is still very much in its infancy across most of the continent.

3. there is much enthusiasm amongst respondents for developing the potential of e-learning in their universities.

However, respondents also identified key constraints in seeking to implement and develop e-learning practices, including the lack of infrastructure, the need for appropriate training and capacity development, a lack of relevant digital content, and the cost of implementation. Typical responses thus include the following:

1. Our universities e-learning developments are still at an infancy stage in that we are still working on trying to identify a suitable e-learning platform to adopt for our content development and learner management.

2. Lack of awareness from most of the teachers and heads of our Universities that the use of e-Learning could be a benefice for the teaching or training.

3. lack of financial resources to support the training of the trainers, the production of the contents of eLearning, to adopt another context.

As a result of the investigation into the issue of elearning best practice, the survey engaged with a wide range of stakeholders from different e-learning projects from across Jordanian universities. As a result of investigating these e-learning projects, a number of different levels of maturity could be distinguished in terms of their 


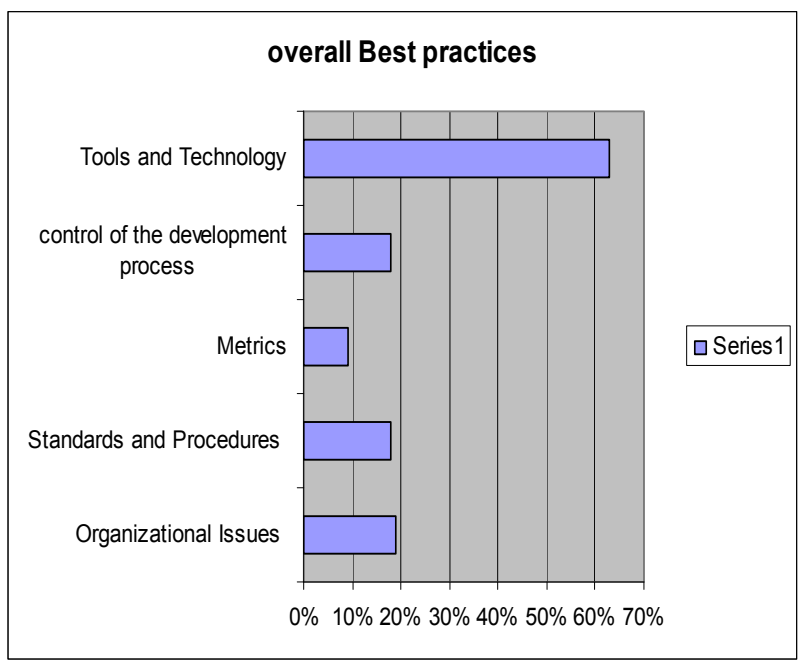

Figure 13. Overall Best practices Adoption Jordanian Universities

planning, development, implementation, evaluation and sustainability. Figure (13) shows the best practices adoption in Jordanian universities.

We have compared our results with a study of Anne Villems and Lehti Pilt [5] and we found that there is a gap between the adoption levels of best practices in European countries and Jordanian universities.

\section{RECOMMANDATION}

The results of the study lead to the following recommendations to improve e-learning development and implementation practice in Jordanian universities:

1. Development teams should be multidisciplinary: elearning implementation process must take into account the different types of developer required to build a successful solution. The process should ensure that all involved understand their roles and responsibilities, and where overlap occurs understand how to resolve conflict in the best interests of the project in question.

2. Universities should apply project management best practices to improve organizational issues.

3. Universities should pay attention to the quality management and standards.

4. Universities should apply software engineering best practices to improve the execution of their e-learning projects.

5. Education and training: A proper and regular training of faculty staff especially on newer aspects in e- learning will lead to an increase of acceptance and usage.

6. Availability of hardware (particularly computers)

7. Faster Internet connectivity/improved bandwidth

8. Improved software

9. Appropriate policies favoring e-learning

10. Provision of technical support for e-learning at a range of scales

11. Lower prices for connectivity

12. Appropriate content in appropriate languages

13. Awareness rising about the value of e-learning

14. Increasing in governmental fund.

\section{CONCLUSION}

E-learning will gradually dominate the teaching learning system. The Ministry of Higher Education in Jordan needs to have some guidelines to help higher learning institutions to implement e-learning successfully and efficiently. The e-learning implementers need to work with elearning standards for common interoperability software. This will promote high quality learning experiences and provide different instructional and learning methods. Teachers and students must have technical and cognitive skills in ICT so that they become effective users of the technology.

\section{REFERENCES}

[1] Hammond, Nick (2003) Learning technology in higher education in the UK: Trends, drivers and strategies. In M. Van der Wende and M. van der Ven (eds), The use of ICT in Higher Education: A mirror of Europe. Lemma Publishers: Utrecht, pp 109-122.

[2] Garrison, D. \& Anderson, T. (2003). E-learning in the 21st Century. London: Routledge Falmer Jaring Internet Magazine 24 March, 2004.

[3] Muneer Mahmood (2009) Looking under the Bonnet: Factors Affecting Student Adoption of E-Learning Systems in Jordan International Review of Research in Open and Distance Learning, Volume 10, Number 2.

[4] IST Programme of the European Commission INNOELEARNING Project (IST-2001-32633 Best Practices in e-Learning Study

[5] Anne Villems, Lehti Pilt 2005 ,UNIVe, Thematic Manual for Staff Development and Support

\section{AUTHOR}

Haroon salem Altarawneh is with Arab International University(AIU), Syrian Arab Republic. E-Mail: haroon@teacher.com

This work was supported by Arab International University (AIU), Syria. Received March $4^{\text {th }}, 2011$. Published as resubmitted by the author May $2^{\text {nd }}, 2011$. 